\title{
Oncology Nurses' Knowledge Regarding Fertility Preservation for Patients with Cancer
}

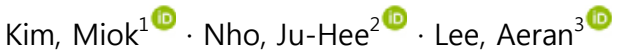 \\ ${ }^{1}$ Assistant Professor, College of Nursing, Dankook University, Cheonan, Korea \\ ${ }^{2}$ Associate Professor, College of Nursing, Chonbuk National University, Jeonju, Korea \\ ${ }^{3}$ Clinical Nurse Specialist, Dongnam Institute of Radiological and Medical Sciences, Department of Cardiac Surgery, \\ Busan, Korea
}

\begin{abstract}
Purpose: Cancer diagnosis and treatment affect patient fertility. Although the reproductive method has been well studied, early assessment of fertility and discussions of infertility-related issues are not very common. This study evaluated oncology nurses' knowledge regarding fertility preservation for patients with cancer. Methods: This study was conducted from March 11 to May 13, 2015 using a convenience sample of nurses who were caring for patients with cancer at a tertiary hospital in South Korea. We recruited 123 oncology nurses and used questionnaires to collect cross-sectional data regarding their knowledge about the causes of fertility impairment (Cause score), fertility preservation in general (General score), and methods of fertility preservation (Method score). Results: The mean total score of fertility preservation knowledge was $15.46 \pm 3.64$, and the mean Cause, General, and Method scores were $6.28 \pm 1.86$ out of $11,5.72 \pm 1.50$ out of 8 , and $3.54 \pm 1.19$ out of 6 , respectively. Significant differences in knowledge levels were found according to nurses' marital status and total nursing experience. Nurses who assessed the issue of fertility upon the first encounter with patients and provided active nursing care had the greatest knowledge. Conclusion: Oncology nurses should have in-depth understanding of fertility preservation and must discuss the topic with patients with cancer. Nurses should also identify each patient's individual needs through continuous assessment and provide referrals to appropriate specialists both before and during treatment.
\end{abstract}

Key Words: Nurses; Knowledge; Fertility; Neoplasms

\section{INTRODUCTION}

Patients with cancer can experience various complications both during and after treatment. Among these complications, problems related to sexual health have been found to have a particularly negative impact on patients' quality of life [1].

Treatment methods, such as chemotherapy and radiation therapy, may lead to decreased sexual desire, menopausal symptoms, vaginal dryness and atrophy, pain during sexual intercourse, and fertility dysfunctions [1,2]. A radiation dose greater than 20 gray can cause male in- fertility by decreasing sperm production, resulting in permanent azoospermia [1], and it may cause females to experience ovulatory dysfunction and early menopause [3]. In patients with reproductive cancers, such as prostate, testicular, and gynecologic cancers, sex-related problems are particularly severe after sexual organ resection [4]. In addition, depression, fatigue, and changes in body image caused by hair loss and skin and weight changes threaten the sexual health of patients with cancer [5]. Cancer treatment typically causes long-term fertility complications $[2,6]$, with $30 \sim 75 \%$ of male patients and $40 \sim 80 \%$ of female patients becoming infertile because of chemotherapy and

Corresponding author: Nho, Ju-Hee https://orcid.org/0000-0002-5260-5605

College of Nursing, Chonbuk National University, 567 Baekje-daero, Deokjin-gu, Jeonju 54899, Korea.

Tel: +82-63-270-3108, Fax: +82-63-270-3127, E-mail: jhnho@jbnu.ac.kr

Received: Apr 1, 2019 / Revised: May 9, 2019 / Accepted: May 27, 2019

This is an open access article distributed under the terms of the Creative Commons Attribution Non-Commercial License (http://creativecommons.org/licenses/ by-nc/3.0), which permits unrestricted non-commercial use, distribution, and reproduction in any medium, provided the original work is properly cited. 
radiotherapy [7]. Hence, cancer treatment negatively affects patients' abilities to complete normal developmental tasks at individual and societal levels, as well as their quality of life [1].

Fertility preservation involves safeguarding patients' reproductive capabilities before performing medical treatment that can cause fertility loss [8]. A great deal of research has focused on preservation approaches such as cryopreservation of sperm, egg, embryo, ovarian tissue, and testicular tissue; ovary transposition; and the use of gonadotropin-releasing hormone releasing agonist $[8,9]$. Reproductive-aged patients with cancer, especially younger patients, desire information on fertility preservation [10]. Hershberger et al.[11] revealed that the provision of information on fertility preservation and medical staff's attitudes are determined by patient preferences, personal values, and the medical staff's in-depth understanding of individual patients' situations. However, medical staff often feel uncomfortable discussing fertility preservation with patients with cancer, and may even avoid the discussion altogether because they lack sufficient knowledge, have little time to discuss relevant issues, and tend to assign priority to treatment aimed at improving survival rates [12]. Studies have shown that $34 \sim 72 \%$ of young patients with breast cancer discuss fertility-related issues with their physicians [13], and many female patients feel their concerns are not appropriately addressed in discussions with their physicians [13].

Although the need for specialized sexual health education for patients with cancer has been continuously suggested, most existing programs focus on the physical symptoms of sexual problems and sexual function management, while fertility preservation has largely been excluded [14]. Logan and Anazodo [15] conducted a global systematic analysis of 33 fertility preservation guidelines and reported that 29 of them provided clinical recommendations on fertility counseling, indicating that fertility counseling is an important part of counseling for all cancer patients. Oncology nurses need to educate patients' families about infertility risks and other fertility-preserving issues [16], and can actively get involved in patients' decision-making process regarding their treatment choices [17].

Fertility preservation counseling and education programs need to sensitively address individual patients' situations; thus, nurses should enhance their understanding of potential fertility-related problems, fertility preservation options, and how to help patients make proper decisions by providing systematic information. Therefore, nurses' current level of knowledge regarding fertility pre- servation should be examined. Accordingly, this study aimed to investigate nurses' level of knowledge of fertility preservation for patients with cancer, and to create a measurement scale that can be used to develop educational materials and guidelines.

\section{Objectives}

The specific objectives of this study were as follows: 1 ) to investigate nurses' knowledge regarding fertility preservation; 2) to analyze level of knowledge regarding fertility preservation, according to nurses' general characteristics; and 3) to examine nurses' characteristics and analyze their level of knowledge concerning fertility preservation based on these characteristics.

\section{METHODS}

\section{Design}

We used a descriptive cross-sectional design to investigate nurses' level of knowledge and the relevant general characteristics regarding fertility preservation for patients with cancer.

\section{Participants}

The participants were nurses from two tertiary hospitals in South Korea (one in Seoul, one in Pusan). On the basis that preceptorship requires more than three months and the time needed for adaptation to the work is more than six months [18], we recruited oncology nurses who had been caring for cancer patients for more than three months and who had clinical experience of more than six months. The minimum sample size required by Cohen's power analysis was $\mathrm{n}=100$ on the assumptions of a significance level of .05 , a medium effect size for correlation between variables of .30 , and a power level (1- $\beta$ ) of .80 computed using $G^{*}$ Power 3.1.9.2. To accommodate participant dropout, we distributed the survey to 125 nurses. After two were excluded because of missing responses, 123 surveys were included in the final data analysis.

\section{Measures}

\section{1) Nurses' knowledge regarding fertility preservation}

We used a modified instrument to measure nurses' knowledge of fertility preservation after reviewing the items employed in prior fertility-related studies [19-21] and consulting experts in the field. 
The initial instrument comprised 30 items. Its content validity was tested by a group of six professionals (one oncologist, two nursing professors, two oncology head nurses with over 10 years of experience, and one oncology nurse practitioner). Based on the opinions of the experts, the items were revised, and items that were not related to fertility preservation knowledge were removed. Among 30 questions from the initial instrument, the Item-level Content Validity Index (I-CVI) of the 25 items was .90 1.00 , which was above the reference value of .78 [22], and five items were removed because they did not meet the criterion. Scale-level Content Validity Index (S-CVI)/ Ave (averaging) was .96, which met the criterion of 90 or higher [23]. We conducted a preliminary survey for the 25 selected items with five oncology nurses working in the ward. Through this process, we identified items that were difficult to understand or answer. The preliminary survey determined that there were no major problems such as with the degree of understanding of questions, response time, placement of items, and adequacy of item length. The items were divided across three subdomains: knowledge regarding the causes of fertility impairment (11 items), general knowledge about fertility preservation (8 items), and methods of fertility preservation (6 items). The response categories for each item were "yes/correct" $=1$ and "no/incorrect/do not know" $=0$. Negative items were reverse coded. The range of total scores was $0 \sim 25$ points, with higher scores indicating a higher level of knowledge regarding fertility preservation.

\section{2) General characteristics and characteristics related to nurses' fertility preservation knowledge}

We used nine items to assess nurses' general characteristics, including gender, age, marital status, religious orientation, education, department, length of nursing experience, length of oncology experience, and job position. Nine more items were used to collect data on nurses' characteristics concerning fertility preservation, perceived need for education on fertility preservation, perceived need for a specialized course on fertility preservation, existence of workplace guidelines, perceived need for educational materials, the first patient characteristic to consider, the most appropriate timing for the assessment, how to approach the topic of fertility preservation, the tools or data used, and beliefs about who should lead the discussion with patients about fertility preservation.

\section{Data Collection}

This study was conducted from March 11 to May 13,
2015 using a convenience sample of nurses who were caring for patients with cancer at a tertiary hospital in South Korea. Data were collected using a survey administered during an interview with nurses. The interviews were conducted in a quiet, comfortable room, where possible, and each lasted 10 to 15 minutes.

\section{Ethical Considerations}

This study was approved by the institutional review board of Dongnam Institute of Radiological and Medical Sciences (IRB no. D-1503-010-002). All nurses provided written informed consent after we explained the study objectives, assured them that participation was completely voluntary and would not be disadvantageous to them in any way, and that they could refuse to participate at any time. We preserved their anonymity by indicating private information with covert symbols.

\section{Data Analysis}

Data were analyzed using SPSS/WIN 21.0. General characteristics, characteristics regarding fertility preservation, and level of knowledge regarding fertility preservation were analyzed with descriptive statistics. To investigate the level of knowledge regarding fertility preservation according to both general and fertility preservation characteristics, we performed an independent t-test, a $x 2$ test, and an analysis of variance with post hoc tests following the data normality test.

\section{RESULTS}

\section{Nurses' Knowledge of Fertility Preservation}

The mean score for knowledge regarding fertility preservation was $15.46 \pm 3.64$, which was above average, given the range of $0 \sim 25$. The mean scores for the subdomains of knowledge level regarding fertility preservation were as follows: $6.28 \pm 1.86$ (range: 0 11), $5.72 \pm 1.50$ (range: 0 8) and $3.54 \pm 1.19$ (range: $0 \sim 6$ ) for causes of fertility impairment (Cause score), general knowledge of fertility preservation (General score), and specific knowledge of fertility preservation methods (Method score), respectively (Tables 1, 2).

\section{Knowledge Level Regarding Fertility Preservation by Nurses' General Characteristics}

In terms of the nurses' general characteristics, there was 


\section{Causes of fertility impairment}

1 In the case of testicular and ovarian cancer, the tumor often causes infertility.

2 In the case of cancers like brain tumors and Hodgkin's lymphoma, infertility occurs even before cancer treatment starts.

3 All chemotherapeutic agents cause infertility.

4 Some chemotherapeutic agents have a lower likelihood of causing infertility than others do.

5 Infertility that occurs because of chemotherapeutic agents is irreversible.

7 Although chemotherapeutic agents affect men's sperm production, this can typically recover after 2 3 months.

14 In the case of brain tumors, including a pituitary gland tumor, infertility can result from a hormonal imbalance.

16 The risk of infertility is higher when the radiation dose is 2.5 gray or greater.

21 A single high dose of radiation is more toxic to the sexual organs than multiple fractionated doses are.

22 Cranial irradiation does not affect fertility.

23 Biologic agents, like bevacizumab, do not have ovarian suppression side effects.

\section{General knowledge about fertility preservation}

6 Fertility evaluation is more difficult in female than in male patients.

11 Age is an important factor to consider concerning fertility preservation.

12 Gonadal dysfunction in men differs by cancer type, patient age, and the cancer treatment dose.

15 Disease prognosis is an important factor to consider in regard to fertility preservation.

17 Practical options are lacking for fertility preservation in men under the age of 13 years whose testicles have not yet fully developed.

19 Older women have less ovarian reserve compared to younger women.

20 Pregnancy is possible in all cases in which menstruation restarts after cancer treatment is complete.

25 In cancer patients, sexual dysfunction and fertility preservation are separate issues.

\section{Methods of fertility preservation}

8 Oocyte cryopreservation is the best method for female fertility preservation.

9 Surgical repositioning of the ovaries can be used to prevent ovarian exposure to radiation.

10 Ovarian functions can be artificially suppressed to preserve fertility.

13 Patient consent is required for all methods of fertility preservation.

18 Sperm banking is the simplest and surest method of male fertility preservation.

24 Ovarian tissue cryopreservation can be used for woman who have not started menstruating and are about to start toxic treatment therapy.

a significant difference in knowledge level regarding fertility preservation based on marital status $(16.49 \pm 2.96$ and $14.77 \pm 3.89$ for married and unmarried nurses, respectively, $\mathrm{t}=2.63, p=.010$ ). Additionally, the knowledge level was significantly different depending on total nursing experience $(16.53 \pm 2.86$ and $15.11 \pm 3.81$ for nurses with over 120 months and under 120 months of experience, respectively, $\mathrm{t}=-2.18, p=.033)$ (Table 3). 
3. Nurses' Fertility Preservation-related Characteristics and Associated Level of Knowledge of Fertility Preservation

Nurses' characteristics related to fertility preservation and levels of knowledge regarding fertility preservation according to these characteristics are shown in Table 4. Regarding the existence of guidelines for fertility preser-

Table 2. Score of Variables about Nurses' Knowledge of Fertility

\begin{tabular}{lcc} 
Preservation & $\begin{array}{c}\text { Scoring } \\
\text { range }\end{array}$ & $\mathrm{M} \pm \mathrm{SD}$ \\
\hline Variables & $0 \sim 11$ & $6.28 \pm 1.86$ \\
\hline Causes of fertility impairment & $0 \sim 8$ & $5.72 \pm 1.50$ \\
$\begin{array}{l}\text { General knowledge about fertility } \\
\text { preservation }\end{array}$ & & \\
$\begin{array}{l}\text { Methods of fertility preservation } \\
\text { Total (25 items) }\end{array}$ & $0 \sim 6$ & $3.54 \pm 1.19$ \\
\hline
\end{tabular}

vation, $9.8 \%(n=12)$ of the nurses responded that their institution had workplace guidelines. Concerning the appropriate timing of fertility preservation assessment, most (74.8\%) chose "Before treatment begins". Regarding how best to approach the subject of fertility preservation, the most commonly selected answer was "Explain or answer a patient's questions" $(69.1 \%, \mathrm{n}=76)$. Regarding the tools or data used when nurses explained fertility preservation to a patient, the most commonly selected answer was "Patient data as well as educational materials developed by experts" $(32.5 \%, \mathrm{n}=40)$, followed by "Educational materials developed by experts" $(26.8 \%, \mathrm{n}=33)$. The presence or absence of institutional guidelines and differences in assessment timing regarding fertility preservation differed according to the level of fertility preservation knowledge $(\mathrm{t}=2.16, p=.032$ and $\mathrm{F}=3.50, p=.018$, respectively). Additionally, the approach, and tools and data used to discuss the subject of fertility preservation showed significant differences ( $\mathrm{F}=3.22, p=.026$ and $\mathrm{F}=2.51, p=.045$, respectively).

Table 3. Level of Knowledge about Fertility Preservation according to Nurses' General Characteristics

$(N=123)$

\begin{tabular}{|c|c|c|c|c|c|}
\hline \multirow[t]{2}{*}{ Variables } & \multirow[t]{2}{*}{ Categories } & \multirow[t]{2}{*}{$\mathrm{n}(\%)$} & \multirow[t]{2}{*}{$\mathrm{M} \pm \mathrm{SD}$} & \multicolumn{2}{|c|}{$\begin{array}{l}\text { Knowledge about } \\
\text { fertility preservation }\end{array}$} \\
\hline & & & & $\mathrm{M} \pm \mathrm{SD}$ & t or $\mathrm{F}(p)$ \\
\hline \multirow[t]{2}{*}{ Gender } & Women & $121(98.4)$ & & $15.55 \pm 3.47$ & $0.39(.700)$ \\
\hline & Men & $2(1.6)$ & & $16.50 \pm 0.71$ & \\
\hline \multirow[t]{3}{*}{ Age (year) } & $<30$ & $63(51.2)$ & $30.3 \pm 6.2$ & $15.02 \pm 3.78$ & $1.11(.334)$ \\
\hline & $30 \sim 39$ & $51(41.5)$ & & $15.80 \pm 3.58$ & \\
\hline & $\geq 40$ & $9(7.3)$ & & $16.55 \pm 2.69$ & \\
\hline \multirow[t]{2}{*}{ Marital status } & Unmarried & $74(60.2)$ & & $14.77 \pm 3.89$ & $2.63(.010)$ \\
\hline & Married & $49(39.8)$ & & $16.49 \pm 2.96$ & \\
\hline \multirow[t]{2}{*}{ Religion } & Yes & $57(46.3)$ & & $15.49 \pm 3.78$ & $-0.10(.919)$ \\
\hline & No & $66(53.7)$ & & $15.42 \pm 3.54$ & \\
\hline \multirow[t]{2}{*}{ Education } & Bachelor's degree & 113 (91.9) & & $15.33 \pm 3.64$ & $-1.22(.224)$ \\
\hline & Master's degree or more & $10(8.1)$ & & $16.80 \pm 3.48$ & \\
\hline \multirow[t]{4}{*}{ Working department } & Internal medicine & $46(37.4)$ & & $15.61 \pm 3.84$ & $0.33(.806)$ \\
\hline & Surgical department & $30(24.4)$ & & $15.73 \pm 3.38$ & \\
\hline & Obstetrics and gynecology & $30(24.4)$ & & $15.37 \pm 3.66$ & \\
\hline & Others & $17(13.8)$ & & $14.71 \pm 3.69$ & \\
\hline \multirow{4}{*}{$\begin{array}{l}\text { Oncology experience } \\
\text { (month) }\end{array}$} & $\leq 12$ & $8(6.5)$ & $48.97 \pm 35.97$ & $16.25 \pm 2.71$ & $0.30(.829)$ \\
\hline & $13 \sim 60$ & $91(74.0)$ & & $15.42 \pm 3.58$ & \\
\hline & $61 \sim 120$ & $15(12.2)$ & & $15.73 \pm 4.64$ & \\
\hline & $\geq 121$ & $9(7.3)$ & & $14.67 \pm 3.50$ & \\
\hline \multirow{2}{*}{$\begin{array}{l}\text { Total nursing experience } \\
\text { (month) }\end{array}$} & $\leq 120$ & $93(75.6)$ & $84.59 \pm 59.14$ & $15.11 \pm 3.81$ & $-2.18(.033)$ \\
\hline & $>120$ & $30(24.4)$ & & $16.53 \pm 2.86$ & \\
\hline \multirow[t]{4}{*}{ Job position } & Staff nurse & $102(82.9)$ & & $15.15 \pm 3.77$ & $1.57(.201)$ \\
\hline & Charge nurse & $4(3.3)$ & & $16.00 \pm 2.58$ & \\
\hline & Clinical nurse specialist & $12(9.7)$ & & $17.25 \pm 2.60$ & \\
\hline & Head nurse or more & $5(4.1)$ & & $17.00 \pm 2.12$ & \\
\hline
\end{tabular}


Table 4. Level of Knowledge about Fertility Reservation according to Nurses' Characteristics

\begin{tabular}{|c|c|c|c|c|}
\hline Variables & Categories & $\mathrm{n}(\%)$ & $\mathrm{M} \pm \mathrm{SD}$ & $\operatorname{tor} \mathrm{F}(p)$ \\
\hline $\begin{array}{l}\text { Need for nursing education } \\
\text { about fertility preservation }\end{array}$ & $\begin{array}{l}\text { Yes } \\
\text { No }\end{array}$ & $\begin{array}{c}7(5.7) \\
116(94.3)\end{array}$ & $\begin{array}{l}14.71 \pm 3.20 \\
15.50 \pm 3.67\end{array}$ & $-0.55(.581)$ \\
\hline $\begin{array}{l}\text { Need for a specialized course } \\
\text { on fertility preservation }\end{array}$ & $\begin{array}{l}\text { Yes } \\
\text { No }\end{array}$ & $\begin{array}{l}99(80.5) \\
24(19.5)\end{array}$ & $\begin{array}{l}15.77 \pm 3.53 \\
14.17 \pm 3.89\end{array}$ & $1.96(.053)$ \\
\hline $\begin{array}{l}\text { Existence of guidelines in the } \\
\text { workplace }\end{array}$ & $\begin{array}{l}\text { Yes } \\
\text { No }\end{array}$ & $\begin{array}{c}12(9.8) \\
111(90.2)\end{array}$ & $\begin{array}{l}17.58 \pm 2.31 \\
15.23 \pm 3.69\end{array}$ & $2.16(.032)$ \\
\hline $\begin{array}{l}\text { Need to establish educational } \\
\text { materials }\end{array}$ & $\begin{array}{l}\text { Yes } \\
\text { No }\end{array}$ & $\begin{array}{l}121(98.4) \\
2(1.6)\end{array}$ & $\begin{array}{l}15.46 \pm 3.63 \\
15.00 \pm 5.66\end{array}$ & $0.18(.859)$ \\
\hline $\begin{array}{l}\text { The first patient characteristic to } \\
\text { consider }(n=117)\end{array}$ & $\begin{array}{l}\text { Gender } \\
\text { Age } \\
\text { Cancer stage } \\
\text { Whether they already have children } \\
\text { Sexual orientation } \\
\text { Sexual needs } \\
\text { Relationship status }\end{array}$ & $\begin{aligned} & (2.6) \\
53 & (45.3) \\
28 & (23.9) \\
12 & (10.2) \\
5 & (4.3) \\
14 & (12.0) \\
2 & (1.7)\end{aligned}$ & $\begin{array}{l}15.33 \pm 1.15 \\
15.98 \pm 3.19 \\
13.75 \pm 4.09 \\
16.17 \pm 3.86 \\
17.20 \pm 3.70 \\
16.14 \pm 3.84 \\
16.00 \pm 7.07\end{array}$ & $1.58(.161)$ \\
\hline Timing of assessment & $\begin{array}{l}\text { Assessment not necessary } \\
\text { At the beginning } \\
\text { Before treatment } \\
\text { During treatment }\end{array}$ & $\begin{array}{c}4(3.2) \\
21(17.1) \\
92(74.8) \\
6(4.9)\end{array}$ & $\begin{array}{l}11.00 \pm 2.94^{\mathrm{a}} \\
16.62 \pm 2.75^{\mathrm{b}} \\
15.51 \pm 3.47 \\
13.50 \pm 6.57\end{array}$ & $\begin{array}{c}3.50(.018) \\
\mathrm{b}>\mathrm{a}^{\dagger}\end{array}$ \\
\hline $\begin{array}{l}\text { How to approach the subject of } \\
\text { fertility preservation }(n=110)\end{array}$ & $\begin{array}{l}\text { No discussion } \\
\text { Explaining, answering } \\
\text { Written data } \\
\text { Explaining, answering+written data }\end{array}$ & $\begin{array}{c}6(5.5) \\
76(69.1) \\
12(10.9) \\
16(14.5)\end{array}$ & $\begin{array}{l}13.00 \pm 2.19^{\mathrm{a}} \\
15.53 \pm 3.66 \\
18.00 \pm 2.83^{\mathrm{b}} \\
15.06 \pm 3.09\end{array}$ & $\begin{array}{c}3.22(.026) \\
b>a^{\dagger}\end{array}$ \\
\hline Tools or data used & $\begin{array}{l}\text { Patient data } \\
\text { Educational materials developed by experts } \\
\text { Online data } \\
\text { Patient data+educational materials } \\
\text { All of the above }\end{array}$ & $\begin{array}{c}29(23.6) \\
33(26.8) \\
17(13.8) \\
40(32.5) \\
4(3.3)\end{array}$ & $\begin{array}{l}13.76 \pm 4.60 \\
16.03 \pm 3.07 \\
15.29 \pm 3.06 \\
16.08 \pm 3.32 \\
17.50 \pm 2.38\end{array}$ & $2.51(.045)$ \\
\hline Who leads the discussion & $\begin{array}{l}\text { Oncologist } \\
\text { Fertility specialist } \\
\text { Oncology nurse } \\
\text { Physician + oncology nurse } \\
\text { Oncologist + fertility specialist } \\
\text { All of the above }\end{array}$ & $\begin{aligned} 26 & (21.1) \\
58 & (47.1) \\
13 & (10.6) \\
9 & (7.3) \\
13 & (10.6) \\
4 & (3.3)\end{aligned}$ & $\begin{array}{l}14.96 \pm 3.62 \\
15.66 \pm 3.44 \\
14.92 \pm 5.06 \\
17.44 \pm 2.51 \\
14.69 \pm 3.09 \\
15.50 \pm 5.45\end{array}$ & $\begin{array}{l}0.83 \\
(.529)\end{array}$ \\
\hline
\end{tabular}

${ }^{\dagger}$ Scheffé test.

\section{DISCUSSION}

This study was conducted to assess the current awareness of fertility preservation among nurses who care for patients with cancer. This was done with the aim of providing the basic data necessary for establishing the relevant guidelines, and to help in preparing nursing interventional programs regarding fertility preservation decision-making.

The mean of oncology nurses' fertility preservation knowledge level was above average, as were the scores on the three subdomains. Armuand et al. [24] observed that neither did most young patients with cancer receive adequate information about fertility preservation nor were they referred to experts in the field, partly because the oncology professionals themselves did not have enough knowledge regarding fertility preservation methods [12]. We measured nurses' knowledge of fertility preservation using an instrument developed specifically for this study; therefore, direct comparisons with previous studies cannot be made. However, future studies must assess whether a moderate level of knowledge of fertility preservation is adequate for nurses to provide sufficient information to patients. 
Patients with cancer can now live longer than was previously possible, owing to improved treatment methods. The increased number of young cancer survivors indicates that quality of life-related topics, including pregnancy following treatment, have emerged as factors to be seriously considered in relation to cancer treatment [25]. Researchers have stressed that medical staff need to inform young patients with cancer about the possibility of post-treatment infertility and offer them an opportunity to choose their preferred method of fertility preservation [26]. Fertility loss causes both psychological distress and decreased quality of life in patients with cancer [27]. Therefore, nurses should make an effort to improve their knowledge of fertility preservation by accepting opportunities to receive relevant information and education.

In this study, the level of knowledge regarding fertility preservation was higher among married nurses. This result is in line with a prior study [28], which reported that fertility preservation choices such as embryo cryopreservation were more common in married or partnered women, showing that fertility preservation choices are affected by marital status It is commonly expected in South Korean culture that once an adult, an individual will get married and become a parent, and this sociocultural point of view also applies to most young patients with cancer. This viewpoint becomes more concrete after marriage, and nurses who are themselves in this stage of life can be empathetic regarding patients' fertility-related problems, such that they explore relevant information to offer help, thereby improving their own knowledge regarding fertility preservation. In a society where it is considered a rite of passage for an adult to become a parent, failure to do so means loss of the most important role in life, as perceived by society [29]. This can lead to either damaged self-affect or the experience of ego crisis among young adults. Eventually, one's entire life can become defined by the infertility status, and patients may consider this their greatest life crisis. Therefore, oncology nurses need to focus on fertility preservation for patients with cancer and establish diverse supportive strategies that account for biological and sociocultural perspectives.

In addition, knowledge of fertility preservation was higher in nurses with more total nursing experience. These results were consistent with a previous study [30]. This seems to be a result of the patient-nurse interactions that occur during the care experience. Throughout the treatment process, from diagnosis to follow-up, nurses share a variety of experiences with patients, including the difficulties associated with the cancer diagnosis and treatment side effects, and the anguish over how to deal with these difficulties. These experiences accumulate as the length of a nurse's career increases, resulting in high nursingrelated knowledge in general and knowledge regarding fertility preservation in particular. Nurses who care for patients with cancer in clinical settings should perform a patient-customized intervention that accommodates the diverse consequences of the cancer type and treatment on fertility. The fears that are commonly felt by patients with cancer should be shared, and it is essential to recognize the need to provide them with adequate information and emotional mitigation and support.

The results of this study show that knowledge regarding fertility preservation was greater among nurses who believed the first patient assessment was the appropriate time to discuss fertility preservation than it was in nurses who responded that there was no particular need to assign a separate time for such a discussion. This finding suggests that even though future fertility is an important item for discussion during the counseling session conducted at the time of cancer diagnosis [26], not all nurses who care for patients with cancer in clinical settings actively make assessments regarding fertility preservation or clearly understand the appropriate timing for such assessments.

Assessing topics related to fertility preservation may negatively affect patients with cancer. If treatment is delayed because of fertility preservation, the cancer may progress or metastasize. The effectiveness of some methods of fertility preservation has not yet been established; therefore, research is in progress, and the overall pregnancy success rate is low [1]. In addition, surgery may be required to extract tissue to freeze, and the hormone used to induce ovarian hyperstimulation to extract eggs can affect the tumor in hormone-sensitive cancers [1]. Nevertheless, patients with cancer can strongly desire fertility preservation and request information to help them choose from among the available options [31]. Accordingly, healthcare professionals need to make careful observations about the benefits and losses patients may experience as fertility preservation technology advances [32]. Medical staff should provide patients with information regarding choices and methods of fertility preservation before performing medical treatment that affects fertility [19], and provide counseling to make a multidimensional assessment that includes the patient's present and future sexual health and enables the striking of a balance between fertility preservation and cancer treatment.

Many nurses simply answered patients' questions or partially explained fertility preservation, rather than initiating an in-depth assessment. Additionally, the level of knowledge regarding fertility preservation was higher 
among nurses who were active in providing nursing care, especially by using written data such as handbooks or brochures, compared to nurses who never provided such care. These findings demonstrated that nurses' attitudes toward sexual health contribute to the nursing care they provide in relation to sexual health. Fertility-related issues are important elements in assessments of patients' sexual health; however, it can be difficult for both parties to approach these issues. According to a previous study conducted in South Korea, both nurses and patients typically have passive attitudes toward sexual health problems [33] therefore, the nursing approach to sexual health problems is, in itself, problematic. As sexual health problems are unfamiliar topics of discussion between healthcare professionals and patients, such that they are often not spoken about in detail unless the patient directly asks about them [34], it can be quite difficult to provide sexual healthcare in clinical settings. Moreover, health care providers tend to focus only on the outcome of cancer treatment, rather than on sexual health problems, because they themselves are not confident in their knowledge of sex-related changes after cancer treatment [35]. Therefore, it is difficult for them to set aside the time to provide sexual counseling to patients, and this leads to inadequate sexual health interventions. One recent study [11] showed that useful strategies to help patients with decision-making with regard to fertility preservation involved providing situationally appropriate information to individual patients using a handbook or website and encouraging positive attitudes among medical staff. Therefore, nurses should have an in-depth understanding of the sexual health-related side effects that can occur during cancer diagnosis and treatment, including issues concerning fertility impairment and preservation, to ensure they can actively assess patients' needs and provide the necessary interventions.

Nurses' knowledge level regarding fertility preservation did not significantly differ based on beliefs concerning who the most appropriate person to discuss the subject matter with patients is; however, $80 \%$ responded that it should be a physician. This indicates that it is desirable to discuss fertility preservation before treatment begins, when a plan for the entire treatment process is made and the scope of treatment determined. Healthcare providers should take medical conditions, treatment plans, and ideal outcomes into account when treating patients with cancer and be aware of a treatment's estimated side effects, including possible effects on future fertility [32]. In addition, nurses, who interact more with patients than do any other oncology team members, should assume the role of counselor with regard to fertility preservation. Nurses who care for patients with cancer should be aware of the fertility-related complications experienced by patients with cancer, and make an effort to perceive and aim to solve individual patients' problems. Furthermore, education that is based on a comprehensive understanding of overall sexual health should be provided to increase nurses' sensitivity to sexual health-related problems, particularly the fertility-related problems of young patients with cancer. Finally, educational materials for patient counseling and education should be developed, and culturally and situationally appropriate guidelines should be established in South Korea.

As this study assessed the fertility preservation-related knowledge of oncology nurses from a single hospital, it is not appropriate to generalize the results. This study did not assess general knowledge related to oncology nursing, which could affect nurses' knowledge of fertility preservation. In addition, the validity of the measurement tool was not precisely examined. Despite such limitations, considering the absence of clear guidelines for fertility counseling and education for cancer patients, the contribution of this study is in helping identify the necessity of all oncology nurses informing and educating patients about fertility preservation throughout the decision-making process, from the diagnosis of cancer to the preparation of treatments.

\section{CONCLUSION}

The increase in the number of young patients with cancer and improved survival rates indicate that fertility preservation has become an important factor affecting the quality of life of patients with cancer. Nevertheless, many nurses who work closely with these patients do not have much knowledge of fertility preservation. Therefore, nurses who handle patient problems, including overall lifetime fertility, should develop a deeper understanding of the possible harmful effects of different cancer treatments on fertility. It is also necessary to identify individual patient needs through continuous assessment and, when necessary, refer patients to appropriate specialists from before the beginning of treatment until its conclusion. Furthermore, nurses should be provided with training to improve their communication skills, especially concerning the subject of fertility preservation, and relevant educational materials and guidelines should be developed.

\section{CONFLICTS OF INTEREST}

The authors declared no conflict of interest. 


\section{AUTHORSHIP}

Study conception, design and data acquisition - KM and NJ-H; Data collection - LA; Analysis and interpretation of the data - KM and NJ-H; Drafting and critical revision of the manuscript - KM and NJ-H.

\section{REFERENCES}

1. Kort JD, Eisenberg ML, Millheiser LS, Westphal LM. Fertility issues in cancer survivorship. CA: A Cancer Journal for Clinicians. 2014;64(2):118-34. https://doi.org/10.3322/caac.21205

2. Schover LR, van der Kaaij M, van Dorst E, Creutzberg C, Huyghe E, Kiserud CE. Sexual dysfunction and infertility as late effects of cancer treatment. European Journal of Cancer. Supplements. 2014;12(1):41-53.

https://doi.org/10.1016/j.ejcsup.2014.03.004

3. Green DM, Sklar CA, Boice Jr JD. Mulvihill JJ, Whitton JA, Stovall $\mathrm{M}$, et al. Ovarian failure and reproductive outcomes after childhood cancer treatment: results from the Childhood Cancer Survivor Study. Journal of Clinical Oncology. 2009;27 (14):2374-81. https://doi.org/10.1200/jco.2008.21.1839

4. Dizon DS, Suzin D, Mcllvenna S. Sexual health as a survivorship issue for female cancer survivors. The Oncologist. 2014 19(2):202-10 https://doi.org/10.1634/theoncologist.2013-0302

5. Byun HS, Chung BY, Kim GD, Kim KH, Choi EH. Factors affecting sexual function of breast cancer women after receiving cancer treatment. Asian Oncology Nursing. 2013;13(2):85-94. https://doi.org/10.5388/aon.2013.13.2.85

6. Ronn R, Holzer HEG. Oncofertility in Canada: the impact of cancer on fertility. Current Oncology. 2013;20(4):e338-44. https://doi.org/10.3747/co.20.1358

7. Brannigan RE. Fertility preservation in adult male cancer patients. In: Woodruff TK, Snyder KA, editors. Oncofertility: fertility preservation for cancer survivors. New York: Springer Science+Business Media; 2007. p. 28-49.

8. Cruz MRS, Prestes JC, Gimenes DL, Fanelli MF. Fertility preservation in women with breast cancer undergoing adjuvant chemotherapy: a systematic review. Fertility and Sterility. 2010;94(1):138-43 https://doi.org/10.1016/j.fertnstert.2009.02.055

9. Klock SC, Zhang JX, Kazer RR. Fertility preservation for female cancer patients: early clinical experience. Fertility and Sterility. 2010;94(1):149-55.

https://doi.org/10.1016/j.fertnstert.2009.03.028

10. Benedict C, Thom B, Friedman DN, Diotallevi D, Pottenger EM, Raghunathan NJ, et al. Young adult female cancer survivors' unmet information needs and reproductive concerns contribute to decisional conflict regarding posttreatment fertility preservation. Cancer. 2016;122(13):2101-9.

https://doi.org/10.1002/cncr.29917

11. Hershberger PE, Finnegan L, Altfeld S, Lake S, HirshfeldCytron J. Toward theoretical understanding of the fertility preservation decision-making process: examining information processing among young women with cancer. Research and Theory for Nursing Practice. 2013;27(4):257-75.

https://doi.org/10.1891/1541-6577.27.4.257

12. Quinn GP, Vadaparampil ST, King L, Miree CA, Wilson C, Raj $\mathrm{O}$, et al. Impact of physicians' personal discomfort and patient prognosis on discussion of fertility preservation with young cancer patients. Patient Education and Counseling. 2009;77(3): 338-43. https://doi.org/10.1016/j.pec.2009.09.007

13. Duffy CM, Allen SM, Clark MA. Discussions regarding reproductive health for young women with breast cancer undergoing chemotherapy. Journal of Clinical Oncology. 2005;23(4): 766-73. https://doi.org/10.1200/jco.2005.01.134

14. Nho J-H. Effect of PLISSIT model sexual health enhancement program for women with gynecologic cancer and their husbands. Journal of Korean Academy of Nursing. 2013;43(5):6819. https://doi.org/10.4040/jkan.2013.43.5.681

15. Logan S, Anazodo A. The psychological importance of fertility preservation counseling and support for cancer patients. Acta Obstetricia et Gynecologica Scandinavica. 2019;98(5):583-97. https://doi.org/10.1111/aogs.13562

16. Breit E. Education for pediatric oncology nurses on fertility preservation of pediatric oncology patients [dissertation]. Orlando, Florida: University of Central Florida; 2014. p. 25-34.

17. Hershberger PE, Sipsma H, Finnegan L, Hirshfeld-Cytron J. Reasons why young women accept or decline fertility preservation after cancer diagnosis. Journal of Obstetric, Gynecologic \& Neonatal Nursing. 2016;45(1):123-34. https://doi.org/10.1016/j.jogn.2015.10.003

18. Anderson G, Hair C, Todero C. Nurse residency programs: an evidence-based review of theory, process, and outcomes. Journal of Professional Nursing. 2012;28(4):203-12. https://doi.org/10.1016/j.profnurs.2011.11.020

19. King L, Quinn GP, Vadaparampil ST, Gwede CK, Miree CA, Wilson C, et al. Oncology nurses' perceptions of barriers to discussion of fertility preservation with patients with cancer. Clinical Journal of Oncology Nursing. 2008;12(3):467-76. https://doi.org/10.1188/08.cjon.467-476

20. Lee SJ, Schover LR, Partridge AH, Patrizio P, Wallace WH, Hagerty K, et al. American Society of Clinical Oncology recommendations on fertility preservation in cancer patients. Journal of Clinical Oncology. 2006;24(18):2917-31. https://doi.org/10.1200/JCO.2006.06.5888

21. Vadaparampil ST, Clayton H, Quinn GP, King LM, Nieder M, Wilson C. Pediatric oncology nurses' attitudes related to dis- 
cussing fertility preservation with pediatric cancer patients and their families. Journal of Pediatric Oncology Nursing. 2007;24(5):255-63. https://doi.org/10.1177/1043454207303878

22. Lynn MR. Determination and quantification of content validity. Nursing Research. 1986;35(6):382-5. https://doi.org/10.1097/00006199-198611000-00017

23. Polit DF, Beck CT, Owen SV. Is the CVI an acceptable indicator of content validity? Appraisal and recommendations. Research in Nursing \& Health. 2007;30(4):459-67. https://doi.org/10.1002/nur.20199

24. Armuand GM, Rodriguez-Wallberg KA, Wettergren L, Ahlgren J, Enblad G, Höglund M, et al. Sex differences in fertility-related information received by young adult cancer survivors. Journal of Clinical Oncology. 2012;30(17):2147-53. https://doi.org/10.1200/jco.2011.40.6470

25. LeeS, Song JY, Ku SY, Kim SH, Kim T. Fertility preservation in women with cancer. Clinical and Experimental Reproductive Medicine. 2012;39(2):46-51. https://doi.org/10.5653/cerm.2012.39.2.46

26. Kim C-H, Jeon G-H. Fertility preservation in female cancer patients. ISRN Obstetetrics and Gynecology. 2012;2012:807302. https://doi.org/10.5402/2012/807302

27. Laganà AS, La Rosa VL, Rapisarda AMC, Platania A, Vitale SG. Psychological impact of fertility preservation techniques in women with gynaecological cancer. Ecancermedicalscience. 2017;11:ed62. https://doi.org/10.3332/ecancer.2017.ed62

28. Lawaon AK, Klock SC, Pavone ME, Hirshfeld-Cytron J, Smith KN, Kazer RR. Psychological counseling of female fertility preservation patients. Journal of Psychosocial Oncology. 2015; 33(4):333-53. https://doi.org/10.1080/07347332.2015.1045677

29. Gerrity DA. A biopsychosocial theory of infertility. The Family Journal. 2001;9(2):151-8.

https://doi.org/10.1177/1066480701092009

30. Yoo JY, Oh EG, Hur HK, Choi M. Level of knowledge on evidence-based infection control and influencing factors on performance among nurses in intensive care unit. Korean Journal of Adult Nursing. 2012;24(3):232-43. https://doi.org/10.7475/kjan.2012.24.3.232

31. Quinn GP, Vadaparampil ST, Malo T, Reinecke J, Bower, B, Albrecht, T, et al. Oncologists' use of patient educational materials about cancer and fertility preservation. Psycho-Oncology. 2012;21(11):1244-9. https://doi.org/10.1002/pon.2022

32. The Ethics Committee of the American Society for Reproductive Medicine. Fertility preservation and reproduction in patients facing gonadotoxic therapies: a committee opinion. Fertility and Sterility. 2013;100(5):1224-31. https://doi.org/10.1016/j.fertnstert.2013.08.041

33. Kim J-H. Factors influencing barriers to addressing patients' sexual health among clinical nurse. Korean Journal of Adult Nursing. 2010;22(2):113-20.

34. Lee GN, Lee D-S. Sexual experiences of women with breast cancer. Asian Oncology Nursing. 2011;11(3):210-20. https://doi.org/10.5388/jkon.2011.11.3.210

35. Kim J-H. Gender role attitudes and barriers in Korean nurses when addressing patients' sexual health. The Journal of Fundamentals of Nursing. 2009;16(3):282-9. 